\title{
Evaluation of the color stability of two techniques for reproducing artificial irides after microwave polymerization
}

\author{
Marcelo Coelho GOIATO', Daniela Micheline dos SANTOS', Amália MORENO², Humberto GENNARI-FILHO', \\ Eduardo Piza PELLIZZER ${ }^{1}$
}

\begin{abstract}
1- DDS, MSc, PhD, Associate Professor, Department of Dental Materials and Prosthodontics, Araçatuba Dental School, São Paulo State University, Araçatuba, SP, Brazil.

2- DDS, MSc, Postgraduate student, Department of Dental Materials and Prosthodontics, Araçatuba Dental School, São Paulo State University, Araçatuba, SP, Brazil.
\end{abstract}

Corresponding address: Prof. Dr. Marcelo Coelho Goiato - Departamento de Materiais Dentários e Prótese - Faculdade de Odontologia de Araçatuba - UNESP 16015-050 José Bonifácio, 1193, Araçatuba, SP - Brasil - Phone: +55-18-3636-3287 - Fax: +55-18-3636-3245 - e-mail: goiato@foa.unesp.br

Received: August 28, 2009 - Modification: May 12, 2010 - Accepted: May 25, 2010

ABSTRACT

The use of ocular prostheses for ophthalmic patients aims to rebuild facial aesthetics
and provide an artificial substitute to the visual organ. Natural intemperate conditions
promote discoloration of artificial irides and many studies have attempted to produce irides
with greater chromatic paint durability using different paint materials. Objectives: The
present study evaluated the color stability of artificial irides obtained with two techniques
(oil painting and digital image) and submitted to microwave polymerization. Material and
Methods: Forty samples were fabricated simulating ocular prostheses. Each sample was
constituted by one disc of acrylic resin N1 and one disc of colorless acrylic resin with the iris
interposed between the discs. The irides in brown and blue color were obtained by oil painting
or digital image. The color stability was determined by a reflection spectrophotometer and
measurements were taken before and after microwave polymerization. Statistical analysis
of the techniques for reproducing artificial irides was performed by applying the normal
data distribution test followed by 2 -way ANOVA and Tukey HSD test ( $\alpha=$. 05 ). Results:
Chromatic alterations occurred in all specimens and statistically significant differences
were observed between the oil-painted samples and those obtained by digital imaging.
There was no statistical difference between the brown and blue colors. Independently of
technique, all samples suffered color alterations after microwave polymerization. Conclusion:
The digital imaging technique for reproducing irides presented better color stability after
microwave polymerization.

Key words: Artificial eye. Paint. Color.

\section{INTRODUCTION}

The loss or absence of eyeball may result from several factors such as congenital defects, irreparable trauma, or oncological problems. Depending on the gravity of the situation, the surgical procedure can include evisceration, enucleation or exenteration ${ }^{11,12}$. Evisceration and enucleation surgeries are extremely traumatic and result in eyeball removal with consequent serious corporal image alterations ${ }^{13,14}$. Such alterations modify the form in which the patient interacts with the others in everyday life ${ }^{14}$.

Since the vision cannot be reconstructed by artificial means, prostheses recover facial esthetics and beautification. In addition, these prostheses promote the sustentation of muscular tonalities of the upper eyelid, allowing tears to be shed into physiological duct and, therefore, avoiding sticking of eyelashes, dryness of conjunctiva, and lack of eyelids development due to lack of function. Furthermore, the prosthesis protects the mucous membrane cavity from debris and dust. As such, the artificial iris is responsible for social reintegration 
of individual and it reduces damages following deficiency which results in improved quality of life regarding social interactions and acceptance of the deformity $6,8,9,12$.

One frequent failure during eye prostheses processing is alteration in iris color. During painting of iris, adequate inks and a dependable technique are necessary; but it is difficult to obtain the exact color of iris mainly when color stability of ink can not be controlled following polimerization ${ }^{9,16}$. In 1945, Murphey, et al. ${ }^{10}$ (1995) affirmed that all colors must remain unchanged during exposure to natural or artificial light. Considering the principles of color formation and the importance of accurate characterization of artificial irides, many authors developed different painting techniques using inks such as watercolors, gouache, oil paint, and automotive paint on different surfaces such as paper, discs of acetate and acrylic resin ${ }^{13,3,4,5,18,19}$.

Recently, printing of digitalized irides on photographic paper has been used for eye prostheses processing to reproduce iris color more faithfully with minimum adjustments and color modifications to provide better esthetics ${ }^{2}$.

Thus, this study aimed at determining, by reflection spectrophotometry, the chromatic stability of irides obtained by printed digitalized imaging or with oil paints following microwave polymerization.

\section{MATERIAL AND METHODS}

A metallic matrix with $15.0 \mathrm{~mm}$ in diameter was used to fabricate discs in colorless autopolymerizing acrylic resin (Clássico, Artigos Odontológicos Clássico Ltda., São Paulo, SP, Brazil) with $1.0 \mathrm{~mm}$ and $2.0 \mathrm{~mm}$ in thickness. These discs were included in flasks for microwave polymerization (Clássico, Artigos Odontológicos Clássico Ltda.) with hard silicone (Zetalabor, Zhermack, Badia Polesine, Rovigo, Italy) and dental stone type III (Gesso-Rio, São Paulo, SP, Brazil).

Forty discs were fabricated with acrylic resin of color N1 for ocular prostheses (Clássico, Artigos Odontológicos Clássico Ltda.) and 40 discs were fabricated with colorless acrylic resin (Clássico, Artigos Odontológicos Clássico Ltda.) for microwave polymerization (Clássico, Artigos Odontológicos Clássico Ltda.). The resin was manipulated according to manufacturer's instructions to fill the molds immediately. The flasks were positioned in a hydraulic press (VH, Midas Dental Products Ltda., Araraquara, São Paulo, Brazil) under $1200 \mathrm{KgF}$ for approximately $2 \mathrm{~h}$. After this period, the resin was polymerized by microwave energy according to manufacturer's instructions. The flasks were inserted in a microwave oven with 1200 Watts of potency (Panasonic, São Paulo, SP, Brazil) during 10 min (3 initial min with $30 \%$ of potency, 4 min with no potency $(0 \%)$, and 3 min with $60 \%$ of power). After natural cooling, the discs were removed after deflasking.

The discs were finished with sandpaper (280-, 320-, 400-, 600- and 1200-grit), and polished with a felt disc and diamonded solution of $1 / 4$ of micron in an automatic polisher (Arotec, Cotia, São Paulo, Brazil). The thicknesses and diameters of all discs were checked by a digital caliper (ME-BA, Zagreb, Yugoslavia), which revealed $15 \mathrm{~mm}$ in diameter for all discs, $2 \mathrm{~mm}$ in thickness for white disks and 1 $\mathrm{mm}$ in thickness for colorless disks. As the thickness values for each disc were defined to simulate the eye prosthesis processing, the layer of colorless acrylic resin deposited around the paint presented $1 \mathrm{~mm}$ in thickness due to the volume of artificial sclera.

The artificial irides were obtained by two techniques. One of the techniques was characterized by painting with an oil-based paint polymer blue (blue cobalt) and brown (land of cassel) $(\mathrm{H}$. Schmincke \& Company, Erkrath, Germany) on discs of white card with $15 \mathrm{~mm}$ in diameter during the same period and under the same conditions of lighting. A drier based on cobalt (Acrilex Special Ink Inc., São Paulo, SP, Brazil), corresponding to $30 \%$ of the weight of the paint, was added to accelerate drying. According to the manufacturer, this product accelerates the drying of the paint but does not modify its behavior on any surface if added in a small quantity before application. For drying the paint, the painting was submitted to infrared light by positioning the discs at $30 \mathrm{~cm}$ distance off an infrared light bulb (E-27, Empalux Ltd, Curitiba, PR, Brazil) of 250 Watts and 130 Volts for $2 \mathrm{~h}$. Twenty artificial irides were obtained by this method representing two colors: 10 painted in blue and the other 10 in brown.

The other technique to fabricate the irides was based on digital images obtained by photographs. The irides painted with blue and brown oil-based paint were digitalized by a digital camera (Canon EOS Digital Rebel, Canon Inc, Tokyo, Japan) with macro lens (Canon Macro Lens EF 100 mm f/2.8 USM, Canon Inc, Tokyo, Japan) and a flash (Canon Macro Ring Lite Flash MR-14EX, Canon Inc, Tokyo, Japan) with time of 125 seconds, focus 16, and sensitivity ISO 640 . The photographs were evaluated and compared to the original image using an imaging software (Photoshop 7.0, Adobe, San Jose, California, USA) for adjusts in color, brightness, contrast and shade².

Twenty irides were printed with $15 \mathrm{~mm}$ in diameter. Ten irides were obtained for each color (blue and brown) on a $20 \mathrm{lb}$ white paper with brightness number 87 (Foolscap HP, HewlettPackard, Palo Alto, CA, USA) using a laser printer 
(HP Deskjet 950C, Hewlett-Packard) with polymerbased paint ${ }^{2}$.

All irides were covered with 3 layers of waterproof fixative spray (Acrilex Special Ink Inc, São Paulo, $\mathrm{SP}, \mathrm{Brazil})^{7}$. Then, the irides were fixed to the discs of resin color N1 with a liquid adhesive (J-305 Monopoly Syrup, Factor II Inc, Lakeside, USA) ${ }^{2}$.

Regarding the assembly of samples, the irides on white resin were positioned on the discs of colorless acrylic resin utilizing the same adhesive previously cited. Each sample was constituted of a disc of acrylic resin color $\mathrm{N} 1$ and a disc of transparent acrylic resin, interpolated by the iris painted with oil paint or obtained by digital imaging. After fixation of the colorless discs, the first reading of color was carried out with a spectrophotometer that measured visible ultraviolet reflection (Shimadzu, Shimadzu Corporation, Nakagyo-ku, Kyoto, Japan); color changes were calculated by the Commission Internationale de I'Eclairage (CIE) L*a*b* system with standard illumination of D65. The CIELab system calculates in the distance between two readings of color through the formula: $\Delta \mathrm{E}=[(\Delta \mathrm{L}) 2+(\Delta \mathrm{a}) 2+(\Delta \mathrm{b}) 2] 1 / 2$, where $L^{*}$ represents brightness, from 0 (black) to 100 (perfect white), a* represents the red (positive value) or green chroma (negative value), while b* represents yellow (positive value) and blue chroma (negative value) $)^{7,10,15}$.

After initial reading, the discs interpolated with the artificial irides were fixed with colorless acrylic resin polymerized by microwave energy (Clássico, Artigos Odontológicos Clássico Ltda.). The resin was mixed and inserted in the flasks under pressure for polymerization with microwave energy as previously described. After that, the samples were removed and submitted to finishing and polishing in an automatic polisher for the second color measurement.

Statistical analysis of the techniques for painting artificial irides was performed by applying the normal data distribution test (Shapiro-Wilk and Kolmogorov-Smirnov) followed by 2-way ANOVA and Tukey's HSD test $(\alpha=0.05)$.

Table 1- $\Delta E$ means (standard deviations) for each technique and color used for reproducing artificial irises

\section{$\Delta \mathrm{E}$ (standard deviations)}

\begin{tabular}{lcc} 
Technique / Colors & Digital imaging & Oil painting \\
\hline Brown & $13.63(1.73)^{\mathrm{Aa}}$ & $21.10(1.88)^{\mathrm{Ab}}$ \\
Blue & $16.68(1.24)^{\mathrm{Aa}}$ & $20.23(1.90)^{\mathrm{Ab}}$ \\
\hline
\end{tabular}

Different uppercase letters in column denote statistically significant difference $(p<0.05)$.

Different lowercase letters in lines denote statistically significant difference $(p<0.05)$.

\section{RESULTS}

The 2-way ANOVA showed that technique was a statistically significant factor $(p<0.001)$ for evaluation of color alteration and there was no significant difference for color, technique and interaction. The Tukey's test indicated statistically significant difference $(p<0.05)$ between the techniques used to fabricate the irides for both colors (Table 1 ).

Although this study did not aim at visually analyzing the color, this approach verified that chromatic alterations occurred in samples with oil paints after polymerization.

\section{DISCUSSION}

Painting of prosthetic iris is a complex stage since it requires rigorous approach to achieve satisfactory results ${ }^{16}$. During painting of the iris, proper paint and technique are required to provide an accurate color since color stability of paint is not controlled after polymerization. For this, several techniques for obtaining prosthetic irides have been developed over the years, such as utilization of custommade irides or prostheses ${ }^{17}$, the use of mixture of monomers/polymers, acrylic pigments ${ }^{4}$, pure pigments, or printed or photographic reproductions of the natural iris of the patient ${ }^{2}$.

In the present study, color alteration was greater than zero for all groups, which indicates chromatic alteration (Table 1 ). This color alteration may have occurred due to the interaction between the components of the paint and the acrylic resin, probably with the residual monomer of resin since all paints were polymers. The reaction between the acrylic resin and the components of the paint during microwave polymerization is still not understood in literature, but it may be suggested that the direct contact of these components affects chemical bonds of the paint and promotes change or breakage in the bonds during polymerization.

In general, significant difference was observed between the different techniques applied to obtain the iris (oil painting and digital imaging) (Table 1 ). A greater alteration in color was recorded for the irides colored with oil paints, also detected visually. Since oil paint requires a long time for complete drying, even with the addition of a specific drier and exposure to an infrared light bulb, a lack of complete drying may have promoted greater instability in the bonds of oil paint components, resulting in greater alterations during polymerization?. Hence, the monomer (methyl methacrylate) may have a significant influence on the paint and lead to accentuated alteration in color. In addition, the substances that compose the paint may have released residues or volatile organic solvents that 
reacted with the acrylic resin deposited around the paint during polymerization.

Table 1 demonstrates that there was no significant difference between the color of the irides, although the brown color has presented a numerically higher chromatic stability compared to the blue color with the technique of the digital printing. According to the literature, dark pigments demonstrate greater resistance to degrading effects generated by natural aging of prosthesis due to formation of more stable chemical bonds that do not break during polymerization 2,3,7. According to Reis, et al. ${ }^{15}$ (2008), significant differences for brown color were observed during artificial aging. However, there was minor final color variation that was clinically acceptable, which is an advantage for the study since irides with dark color are predominant in Brazilian population.

The digitalized printing technique achieved an adequate result regarding the alterations in color after polymerization and may be clinically indicated. However, the iris obtained by this technique presented elevated $\Delta \mathrm{E}$ values, but lower than those obtained by the technique with oil painting. This result caused significant color alteration that was visually noticed. Further studies are required to evaluate color stability of eye prostheses comparing different kinds of techniques and materials to allow the indication of the best technique for clinical use.

\section{CONCLUSIONS}

Within the limitations of this study, the results indicated that both techniques for reproducing artificial irides caused color alterations following microwave polymerization. However, the digitalized iris printing technique presented greater color stability after polymerization. The blue and brown colors exhibited the same trend, independently of the technique used.

\section{ACKNOWLEDGMENTS}

This investigation was supported by The São Paulo State Research Foundation (FAPESP), Brazil.

\section{REFERENCES}

1- Allen L, Webster HE. Modified impression method of artificial eye fitting. Am J Ophthalmol. 1969;67:189-218.

2- Artopoulou II, Montgomery PC, Wesley PJ, Lemon JC. Digital imaging in the fabrication of ocular prostheses. J Prosthet Dent. 2006; 95:327-30.

3- Benson P. The fitting and fabrication of a custom resin artificial eye. J Prosthet Dent. 1977;38:532-8.

4- Couillard P, Schaaf NG. Fabrication of the ocular portion of an orbital prosthesis. J Prosthet Dent. 1976;35:478-81.

5- Dyer NA. The artificial eye. Aust J Ophthalmol. 1980;8:325-7. 6- Fernandes AU, Portugal A, Veloso LR, Goiato MC, Santos DM. Assessment of the flexural strength of two heat-curing acrylic resins for artificial eyes. Braz Oral Res. 2009;23:263-7.

7- Fernandes AUR, Goiato MC, Batista MAJ, Santos DM. Color alteration of the paint used for iris painting in ocular prostheses. Brazilian Oral Res. 2009;23:386-92.

8- Goiato MC, Fernandes AUR, Santos DM, Barão VAR. Positioning magnets on a multiple/sectional maxillofacial prosthesis. J Contemp Dent Pract. 2007;8:101-7.

9- Goiato MC, Mancuso DN, Sundefeld MLMM, Gabriel MBM, Murakawa AC, Guiotti AM. Aesthetic and functional ocular rehabilitation. Oral Oncology Extra. 2005;41:162-4.

10- Lemon JC, Chambers MS, Jacobsen ML, Powers JM. Color stability of facial prostheses. J Prosthet Dent. 1995;74:613-8.

11- Murphey PJ, Pitton RD, Schlossberg L, Harris LW. The development of acrylic eye prosthesis at the national naval medical center. J Am Dent Assoc. 1945;32:1227-44.

12- Paranhos RM, Batalhão $\mathrm{CH}$, Semprini M, Regalo SC, Ito IY, Mattos MG. Evaluation of ocular prosthesis biofilm and anophthalmic cavity contamination after use of three cleansing solutions. J Appl Oral Sci. 2007;15:33-8.

13- Perman KL, Baylis HI. Evisceration, enucleation, and exenteration. Otolaryngol Clin North Am. 1988;21:171-82.

14- Raizada K, Rani D. Ocular prosthesis. Cont Lens Anterior Eye. 2007;30:152-62.

15- Reis RC, Brito e Dias R, Mesquita Carvalho JC. Evaluation of iris color stability in ocular prosthesis. Braz Dent J. 2008;19:370-4. 16- Reitemeier B, Notni G, Heinze M, Schöne C, Schmidt A, Fichtner D. Optical modeling of extraoral defects. J Prosthet Dent. 2004;91:80-4.

17- Song JS, Oh J, Baek SH. A survey of satisfaction in anophthalmic patients wearing ocular prosthesis. Graefe's Arch Clin Exp Ophthalmol. 2006;244:330-5.

18- Sykes LM. Custom made ocular prostheses: a clinical report. J Prosthet Dent. 1996;75:1-3.

19- Taicher S, Steinberg HM, Tubiana I, Sela M. Modified stock-eye ocular prosthesis. J Prosthet Dent. 1985;54:95-8. 